\title{
Evaluating collaborative management of forest from Rangapur CFM, Rautahat
}

\begin{abstract}
Mohan Poudel ${ }^{1}$
Collaborative Forest Management (CFM) is the youngest forestry program implemented so far in Nepal focusing on sustainable management of the Nepal's productive Terai forest. It has been defined as working partnership between the key stakeholders in the management of the given forest. CFM aims to manage the Terai forest through involvement of the local people in decision making, implementation, benefit sharing and monitoring along with local government bodies (DDC, VDC) and national forest authority (DFO). Rangapur is one of the three pilot CFM sites comprising 1472 ha forest with 22 VDCs and a Municipality as command-area in Rautahat district of Nepal. Despite several promising impacts, some weaknesses and threats of CFM have also been realized within its two years of implementation in Rangapur. This paper assesses and evaluates major achievements, strengths, weaknesses, threats and opportunities of CFM hoping useful towards sustainability.
\end{abstract}

Key words: Sustainability, partnership, stakeholders, Rangapur, pilot

C ollaborative Forest Management (CFM) is the youngest forestry program implemented so far, in Nepal. CFM modality in Nepal has been designed focusing on sustainable management of Terai forest. Several policies and strategies formulated and implemented in the past to manage Terai forest resulted unsuccessful. Operation Forest Management Plan (OFMP) and Community Forestry (CF) are the latest example of such efforts. The OFMPs were technically sound plans, but the plans did not address the interests and aspirations of the local people. These plans were formulated with little consultation and were consequently opposed by the local people (Sharma et al., 2004). CF, a very successful model in the hills of Nepal has brought social conflicts in some cases in the Terai. Various authors (Poudel, 2002; Dahal, 2003; NEFUG, 2005; Maharjan, 1998; RDF/ $\mathrm{N}, 2004$ ) have indicated that $\mathrm{CF}$ in the Terai is far more complicated than in the hills.

Although, the CFM modality is also based on participatory approach, the concept within the Terai context is different. It has been developed regarding management of big contiguous blocks of the Terai hardwood forest. It has been developing as partnership approach rather than participatory. In general, it is defined as working partnership among the key stakeholders in the management of the given forest. The key-stakeholders being local forest users and state forest departments, as well as parties such as local governments, civil groups, non-governmental organizations and the private sectors (Carter and Gronow, 2005). Cornwall (1996) and BorriniFeyerabend (1997) have also defined CFM as a working partnership between the key-stakeholders in the management of the given forest. Furthermore, Berkes (1997) has clarified the nature of partnership stressing the importance of "trying to develop equitable partnerships, drawing upon the complementary strengths of the District Forest Offices (DFOs) and the local users" in the comanagement of forest resources. Although CFM in Nepal is still in its initial stage, it seems to be addressing some constraints. CFM working group, (CFM-WG, 2003) which is one of the multistakeholder working groups under the Ministry of Forest and Soil Conservation (MFSC), defines the CFM as an approach of sustainable forest management in collaboration with the local people to achieve multiple benefits, maintaining ecological balance, generating economic returns and improving livelihood from the government-managed forest.

The Government of Nepal intends to manage the Terai forest through the involvement of the local government and people in decision making, implementation, benefit sharing and monitoring. According to the CFM-WG (2003), the main objective of the approach is to develop sustainable forest management in order to i) fulfill the needs for 
forest products, ii) help in poverty reduction by creating employment, iii) maintain and enhance biodiversity, and iv) increase national and local income through active management of the Terai and Inner Terai forest. Currently, CFM is operational in three districts: Bara, Parsa and Rautahat in piloting phase.

\section{Rangapur Collaborative Forest}

Rangapur is one of the pilot collaborative forests in Rautahat district of Nepal. It is located in between Rangapur, Simrae Bhawanipur and Santapur VDCs. It is almost square in shape and comprises Sal and Asna as major tree species. Based on the new forest policy 2000 and CFM directive 2003, the Rangapur CFM unit was declared as a pilot CFM unit. However, the first five year (2003-2008) management scheme was approved on 22 Dec 2004 along with other two pilot schemes (Sabaya in Parsa and Sahajnath in Bara). CFM scheme covers both constitution and management plan of the forest and other development of its command area.

The Rangapur CFM unit covers about 1472 ha of forest area. The total area is divided into different compartments and sub-compartments. There are together 12 compartments each having comprising 100 ha area. Each compartment is further divided into four sub-compartments 25 ha each. About 270 ha area adjoining the villages is defined as fringe area. Most of the fringe areas comprise degraded forest, open grazing land and encroached area. According to the scheme, the Rangapur CFM unit comprises 141.1 cubic meters per ha of average growing stock. Average annual increment is $2.6 \%$.

The management scheme defines 22 VDCs and a Municipality as command-area of the CFM unit. The command-area extends from forest to the Indian boarder. On the basis of accessibility and livelihood dependency on the forest, the command-area is divided into two types: close and distant. The users living at the vicinity of the forest (not more than 5 $\mathrm{km}$ distance from the forest) are called close users. It is believed that their livelihood system highly depend on the forest resources. There are five close VDCs i.e. Chandranigahapur, Santapur, Dumaria, Rangapur, and Simra Bhawanipur. Other 16 VDCs and a Municipality (Gaur) are called distant VDCs. The scheme has also defined role and responsibilities seprately for both close and distant users. There are 27,011 households with a population of 162,611 people (DDC 2002). The male:female ratio is 51:49.
Average population growth rate is $2.2 \%$ (Cencus, 2001).

The scheme projected about $10 \mathrm{cft}$ timber and 5,700 $\mathrm{kg}$ fuelwood demand per household per year. Looking at the figures, there is a huge gap between the users' demand and supply capacity of the forest. About $70 \%$ timber and $90 \%$ fuelwood deficits are projected by the scheme. Regarding the facts, different managerial prescriptions have also been prescribed by the scheme. Annual harvesting prescription, stand improvement activities, forest development in both the public and private land, promotion of NTFPs, livelihood strategies, income generation activities etc are some important features of the scheme to meet the objectives.

\section{Achievement so far towards institutional development and group mobilization}

From the initial days of BISEPT-ST, CFM movement was also started in Rautahat. There were series of seminars, workshops, field-visits, group meetings, discussions and group formation within and outside the district. Major achievement towards institutional development and group mobilization so far are:

- Series of workshops and meetings have been organized to introduce and justify CFM concept and its modality among the local people, government officials, DDC members, local politicians, local NGOs, media persons and CFM experts.

- CFM constitution (Rangapur CFM Scheme 20032008) has been approved by the Government of Nepal. All social mobilization activities going on are directed by the scheme.

- Rangapur CFM adhoc committee has been formulated according to the CFM Directive 2003. The adhoc committee has started several extension activities: organized meetings in each and every village, finalized command-areas (VDCs), miking, postering, radio programs, street drama etc.

- Different sectoral sub-groups have been formed and brought into action. Protection sub-groups are developed in close VDCs regarding timber smuggling problem. Other functional sub-groups developed so far are depot management subgroup and income generating activities (IGA, women) sub-group. At present, the sub-groups are in course of their institutionalization. They have their own decision making, record keeping 
and patrolling system. They are free to determine firewood and small timber prizes for the purpose of internal use. So far, there are six protection, two depot management and an IGA women subgroups. The adhoc committees in support of the DFO perform other regular activities of forest management and social mobilization.

- A CFM implementation unit has been formulated and is now functioning. It has its own office at Chandra Nigahapur Regular meeting, planning, implementing and progress reporting systems are going on.

- Group formation process is in progress. Elections for the VDC/ward members have been completed. Although it took long time, the first general assembly for the election of CFM committee members have also been completed.

- Two social mobilizers have been appointed since last year and are regularly working in their respective field.

\section{Achievements towards sustainable forest management}

BISEP-ST has assisted in almost all steps of designing and establishing the Rangapur CFM unit in Rautahat. The Rangapur forest area has always been under high pressure of illegal cutting of timber for smuggling, heavy grazing and encroachment mostly from new immigrants. As a result, most of the forest area is degraded and under stocked. However, within four years of CFM introduction and two years of scheme implementation, some important and remarkable achievements have been made. They are:

- Preparation and approval of CFM Management Scheme (2003-2008) from the forest authority of Nepal is an important achievement towards sustainable CFM. The scheme comprises almost all data about forest, growing stocks, ecological condition, species composition, wildlife and their habitats. The scheme has divided the forest areas into different units recommending respective management prescriptions on the basis of forest condition. It has projected annual allowable cut, annual operation cost and annual income. It has also recommended other different important activities. Most of the activities are focused on sustainability of CFM. Some important activities are: forest development in public and private lands, income generation activities in fringe areas, social development, bio-diversity protection and livelihood strategies.
- Ground truthing of compartments and subcompartments has been completed. Strips of $5 \mathrm{~m}$ and $3 \mathrm{~m}$ width between the compartments and sub-compartments are used for the purpose of patrolling and fire control. Each compartment consists of four sub-compartments of 25 ha each. Besides, there are few sub-compartments in the fringe area too. On the basis of growing stocks and regeneration status, some sub-compartments have been treated as regeneration-protection, seeding-felling and coppice-management plots. Collection of dead/dying trees has been going on throughout the forest.

- More than 20 ha open grazing field in the fringe area has been planted. With active participation of the local protection sub-group, plantation site has been protected enthusiastically. The sab-group members are not only protecting but also getting benefit from grass. Furthermore, they are satisfied with the newly emerging green shoots around their village. Similarly, 20 ha shrub land near by the plantation site has also been set aside as regeneration-protection area. It has also resulted very impressive.

- About 40ha public land has been planted in different VDCs of the command-areas during the last two years. Most of the public lands are school or VDC-office compounds, road sides and canal sides.

- Timber smuggling, uncontrolled firewood collection and encroachment have significantly been controlled within the CFM area. It is mostly because of the joint venture of DFO staff and protection sub-group members. Joint meeting of CFM adhoc committee and sub-committees have decided that only two days (sat\&wed) in a week well be allowed to the local people to collect firewood.

- Regarding firewood problem in the distant VDCs, two firewood sales depot have been established and are running.

- Forest development programs in the private and public lands focussed mostly on distant VDCs has been started through NGOs.

- Different skill-development trainings such as bamboo handicraft, small saving-credit, NTFP cultivation, Tapari (from sal leaf), bee keeping etc. have been going on. The local NGOs and Women Development Offices (WDOs) are mostly conducting such activities. 


\section{Strengths, Weaknesses, Opportunities and Threats}

The information and arguments presented here are mostly based on learning experiences gained from the field implementation of CFM in Rangapur, Rautahat. Apart from this, the proceedings and reports of various meetings and workshops with the CFM adhoc committee members, sub-committee members (from Bara and Parsa districts also) and suggestions from the BISEP-ST officials have also been taken into consideration.

\section{Strengths}

- CFM has addressed, incorporated and brought all the essential stakeholders deprived of essential rights into active management mode of the Terai forest. The CFM-WG consists of both close and distant users. Distant users are also benefiting from the revenues and other benefits from the forest (CFM unit). Furthermore, CFM represents and involves wide range of people including NGOs, women, dalits and poor in decision making.

- CFM has been found to have created strong awareness and ownership among all the partners and stakeholders. The institutional system penetrates the grassroot-level for decision making. Provision of public auditing and joint monitoring seems to have boost up the feeling of ownership. Furthermore, the activities of the protection subcommittee and their initial impacts have been clearly leading towards better forest protection and more responsible management.

- There will be a flow of revenues that can be used for development of the CFM command-area. Income as a result of CFM scheme implementation can be used for livelihood options, social development, forest and greenery development, NTFP cultivation etc.

- The forest and biodiversity will be managed in a sustainable manner under the guidance of technically sound and reliable management scheme. The production over time will increase as it is anticipated that the condition of forest will improve. The revenues derived will be legal and traceable, thus minimizing the illegal circuit.

- CFM has already indicated that it will be very much capable to reduce encroachment and timber smuggling from the CFM unit (forest).

\section{Weakness}

- The CFM institutional structure is big and seems conflicting. The command-area of Rangapur CFM for example, consists of 21 VDCs and a Municipality. Selecting a group member from each ward from the remote and politically conflicted area is not an easy task. Furthermore, election of CFM Committee from CFM-WG assembly of more than 250 members require high skill of group facilitation. Because of these problems, indeed, the adhoc committee has faced difficulties and taken long time to organize group assembly. Provision of DDC nominating CFM Committee chairperson seems to be creatitng more conflict among the committee members and thus, may not be so effective.

- Diverse needs and interests of huge population from close to distant. VDCs may be another weakness of CFM.

- CFM may result better control and protection over the forest. Because of better protection, potential conflicts and confrontations may occur between timber smugglers and CFM-WG member protecting the forest.

- Majority of the distant users are not aware of CFM and have not yet internalized the concept. Because of the large area and huge population there are always possibilities of support-gap, which means that the close users may give full support whereas the district users may not towards CFM.

- The production and distribution of forest products as per the demand is difficult to realize. Bringing so many households with different needs and interests into common decision is not an easy task. Fixing prize, establishing control mechanism for fire wood collection and rehabilitation of the encroached areas are some of the important issues in this regard.

- CFM Directives 2003 is not clear about the revenues sharing among partners of CFM. The limited proposed share for people and district could jeopardize participation.

\section{Opportunities}

- CFM seems effective towards sustainable management of the Terai forest through implementation of CFM scheme that has been developed through combine efforts of all the concerned partners and technical experts. It would be huge opportunity to stop the on-going forest 
degradation and institutionalization of illegal circuits. Joint venture of the local people, local government and forest authority may create check and balance situation among all the stakeholders including forest officials, timber smugglers, firewood traders, saw millers and local users.

- CFM has potential to contribute towards poverty reduction. Revenues going to the users can be used for the purpose of poverty reduction through different income generating activities. The first five-year (2003-2008) plan of Rangapur CFM has projected revenue of NRs 96,60,000. A part of the revenue derived from CFM can be used for different development activities in order to contribute development of social sector.

- Proper implementation of CFM scheme could create considerable employment opportunities. Timber harvesting, scientific treatments, forest development, social mobilization etc. are some activities that require lots of both skilled and unskilled employees. People are involved in illegal cutting, timber smuggling, firewood trading can be employed in such activities, and their livelihood strategy may change towards sustainable CFM

- CFM will fuel forest sector decentralization process and make it sustainable.

- CFM will be able to address biodiversity in its area more effectively by identifying biodiversity hotspots.

- CFM networking would increase and establish as a pressure-group advocating rights and responsibilities of the users leading towards sustainable CFM.

- CFM offers an opportunity to promote and intensify private and public land forestry in distant VDCs.

- $\mathrm{CFM}$ as a participatory and decentralized sustainable forest management model can be replicated in other districts of the Terai. If resulted as anticipated, it could be another internationally appreciated model of Nepal.

\section{Threats}

- Anti CFM campaign that has been led by the FECOFUN is one of the major threats of CFM to be established as sustainable participatory forest management model in the Terai. It has been experienced in the Rangapur CFM area also. They have started anti-CFM campaign mostly in close VDCs creating confrontation between the users, delivering anti-CFM messages. According them: i) unlike $\mathrm{CF}$, CFM restricts users' right of decision making and benefit sharing independently. ii) $\mathrm{DFO}$ will have more control over the resources, and iii) Close users may loose their right to access the forest for their daily needs.

- Threats have also been realized because of the confusing views of some forestry experts and civil society. Some are supporting the FECOFUN's views.

- The ongoing political crisis may hamper institutional strengthening and implementation of management scheme.

- Traditional (not consulting people) concept of field level DFO staff may bring CFM into conflicts.

- People's and Government's acceptance as well as commitment towards scientific forest management are still to be developed. For years there has been a ban on felling green trees.

- The government normally applies rules and regulations in a rigid manner. If same happens during application of CFM directive 2003 and approved schemes in piloting phase, it may hamper CFM. At this stage, CFM should be treated in a flexible way.

- Confusion over revenue sharing between the government and the users seems to be a major threat to gear CFM in the Terai. If the government is not willing to come forward with a more realistic benefit sharing mechanism, the CFM-WG members may loose interest towards the CFM modality.

- If no alternative means are developed for the large number of households involved in fuel-wood collection for their survival, big social problems may arise.

- Strong network of timber smuggling may always try to fail CFM.

\section{Discussion and Recommendations}

The CFM model itself is not sufficient to ensure sustainability which always remains dynamic with the existing policies and practices. The existing policies and implementing strategies should always be socially acceptable, economically viable and environmentally appropriate. Therefore, at this stage of CFM implementation, management should be flexible as per the existing policies and implementing strategies. The management should always be guided through learning by doing approach. The weaknesses and threats should either be converted into strength or avoided through possible alternatives. Some suggestions in this regards are: 
- There is urgent need to develop basic criteria for CFM formation. Looking at Rangapur, there are some disputes regarding the CFM unit (forest) and its command-area. The CFM command area should be increased to reduce huge gap between users' resource demand and supply capacity of the existing management unit projected by the scheme. There is also a need to define clear borderline between the close and distant users.

- Issues that are raised by different persons, institutions including the FECOFUN should be taken into account while implementing CFM programs. Compensation for losing free assess of the close users can be given through the possibility of NTFP cultivation in the fringe-areas of the forest, giving them labor opportunities during harvesting operation. Most importantly, the fringe-areas can be handed over to them (villagers near by) as small community forests under the CFM.

- Effective awareness campaign should always be carried out throughout the command-area to bond people with strong ownership feeling.

- The institutional structure of the CFM-WG should be reviewed to make it small and efficient. The CFM chairperson should be elected from the users rather than nominated by the DDC.

- In order to control illegal cutting and trade of fuel-wood and timber, efficient collection and distribution mechanism of forest products should be established throughout the command-areas. Promotion of agro-forestry in private and public lands, promotion of bio-gas, promotion of IGAs by creating labor opportunities may change livelihood strategy and ultimately protect forest and optimize its production potential.

- Regulation of access is necessary, but the provision of the alternatives should be first before totally closing the forest. Livelihood strategy for those who are involved in timber and firewood smuggling should be changed towards income generation from the fellow/public lands. NTFPs cultivation, intercropping (cash crop), and pasture development for productive livestock farming could be the major activities in this regard. This issue can be addressed in the constitution based on the field reality.

- The CFM scheme should be reviewed regularly and updated on the basis of the experiences and feedback from participatory-evaluating mechanism.
- Existing confusions over power and benefitsharing among the partners should be resolved as soon as possible so to avoid possible frustration among the users. A fair benefit-sharing mechanism between the government and the users should be developed. More revenues should stay within the district in order to sustainably address the NRM sector at grassroot level.

- DFO staff (deputed to the CFM implementing unit) should be recruited along with the CFM Committee and other related community mobilizers. They should internalize the theme of CFM to lead forward as they are responsible for the administrative, financial and management of the CFM scheme.

\section{Conclusion}

Although it would be early to say that CFM ensures its sustainability, it seems promising. From the experience gained so far, it has been realized that CFM is the model (approach) what the forest resources in the Terai Nepal is looking for.

\section{References}

Berkes, F. 1997: New and not-so new directions in the use of the commons: co-management. The Common property Resource Digest 42:5-7

BiSEP_ST/RSU. 2005a: Proceedings of RFCC meeting. Biodiversity Sector Programme for Siwalik and Terai, Regional Support Unit, Hetauda

BiSEP_ST/RSU. 2005b: Proceedings of Collaborative Forest Management Committee Interaction workshop. Biodiversity Sector Programme for Siwalik and Terai, Regional Support Unit, Hetauda

BiSEP_ST/RSU. 2005c: Proceedings of Collaborative Forest Management Committee meetings. Biodiversity Sector Programme for Siwalik and Terai, Regional Support Unit, Hetauda.

BISEP-ST/RSU. 2006. Present status of implementation of CFM Schemes, Bio-diversity Sector Programme for Siwalik and Terai, Regional Support Unit, Hetauda BISEPT-ST report

Borrini-Feyerabend, G. 1997. Participation in conservation: why, what, when, how ? In Beyond fences: seeking social sustainability in conservation. (ed) Borrini-feyerabend, G., IUCN, Gland, Switzerland 26-31. 
Carter, J. \& Gronow, J. (2005). Recent Experiences in Collaborative Forest Management. A review paper, CIFOR, Occasional Paper No. 43.

CFM- Working Group of FSCC, 2003. Framework for Collaborative Forest Management in Nepal. Ministry of Forest and Soil Conservation, Kathmandu, Nepal.

Cornwall, A. 1996. Towards participatory practice: PRA and participatory process. In Participation and health (ed).

DDC. 2002. Dekoning, K. Rautahat at Glance, Brochure, DDC, Rautahat
HMG-MFSC. 2003. Collaborative Forest Management Manual 2003

HMG-MFSC. 2005a. Draft Collaborative Forest Management Manual 2005

HMG-MFSC. 2005b. District Forest Coordination Committee (Establishment and Operational) Directive (2062)

Rangapure CFM 2004. Management Scheme for 2003-2008 of Rangapure Collaborative Forest, Rautahat, Nepal 